\title{
Sexual Dimorphism in the Spinal Cord Is Absent in Mice Lacking the Ciliary Neurotrophic Factor Receptor
}

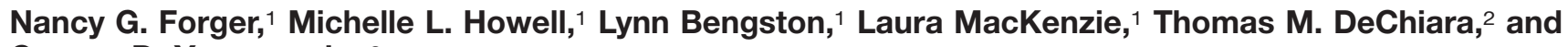 \\ George D. Yancopoulos² \\ ${ }^{1}$ Department of Psychology and Center for Neuroendocrine Studies, University of Massachusetts, Amherst, \\ Massachusetts 01003, and ²Regeneron Pharmaceuticals, 777 Old Saw Mill River Road, Tarrytown, New York 10591
}

Ciliary neurotrophic factor (CNTF) has potent survivalpromoting effects on motoneurons in vitro and in vivo. We examined knockout mice with null mutations of the gene for either CNTF itself or the $\alpha$-subunit of the CNTF receptor $(\mathrm{CNTFR} \alpha)$ to assess whether CNTF and/or its receptors are involved in the development of a sexually dimorphic neuromuscular system. Male rodents have many more motoneurons in the spinal nucleus of the bulbocavernosus (SNB) than do females. This sex difference is caused by hormone-regulated death of SNB motoneurons and their target muscles. Sexual dimorphism of SNB motoneuron number developed completely normally in CNTF knockout (CNTF -/-) mice. In contrast, a sex difference in the SNB was absent in $\operatorname{CNTFR~} \alpha-/-$ animals: male mice lacking a functional CNTF $\alpha$-receptor had fewer than half as many SNB motoneurons than did wild-type males and no more than did their female counterparts. Size of the bulbocavernosus and levator ani muscles, the main targets of SNB motoneurons, was not affected in either CNTF or CNTFR $\alpha$ knockout males. These observations suggest that signaling through the CNTF receptor is involved in sexually dimorphic development of SNB motoneuron number and that target muscle survival per se is not sufficient to ensure motoneuron survival in this system. In addition, our observations are consistent with the suggestion that CNTF itself is not the only endogenous ligand for the CNTF receptor. A second, as yet unknown, ligand may be important for neural development, including sexually dimorphic motoneuron development.

Key words: motoneuron; androgen; sexual dimorphism; ciliary neurotrophic factor; knockout mice; androgen
Naturally occurring death of motoneurons is a widespread phenomenon in the developing vertebrate nervous system. Approximately one-half of all motoneurons generated in the spinal cord die during a prenatal period of cell death (Hamburger, 1975; Chu-Wang and Oppenheim, 1978; Lance-Jones, 1982; Harris and McCaig, 1984). Cell death begins after motoneurons have made contact with their target muscles, and signals from muscles appear to be important for controlling the magnitude of motoneuron loss (Hamburger, 1975; Oppenheim, 1991). Several recently purified neurotrophic factors can enhance motoneuron survival in developing animals when supplied exogenously, although it is not known which, if any, of these trophic molecules are the physiologically relevant signals normally regulating motoneuron death (for review, see Ip and Yancopoulos, 1996; Oppenheim, 1996).

A special case of naturally occurring motoneuron death is seen among sexually dimorphic motor pools, such as the spinal nucleus of the bulbocavernosus (SNB) of rodents. The SNB is a cluster of motoneurons in the lower lumbar spinal cord that innervates striated perineal muscles including the bulbocavernosus (BC), levator ani (LA), and external anal sphincter (Schröder, 1980; McKenna and Nadelhaft, 1986). The BC/LA complex wraps around the rectum and the base of the penis and mediates sexual

Received July 15, 1997; revised Sept. 15, 1997; accepted Sept. 26, 1997.

This work was supported by National Institutes of Health Grant HD33044 and the Whitehall Foundation. We thank Anthony Lucarelli for excellent technical assistance and Elizabeth Connor for helpful comments on an earlier version of this manuscript.

Correspondence should be addressed to Nancy G. Forger, Department of Psychology, University of Massachusetts, Amherst, MA 01003-7710.

Copyright (C) 1997 Society for Neuroscience $\quad 0270-6474 / 97 / 179605-08 \$ 05.00 / 0$ reflexes such as erection and ejaculation (Sachs, 1982; Wallach and Hart, 1983).

$\mathrm{BC} / \mathrm{LA}$ muscles and SNB motoneurons initially form in prenatal rats of both sexes. The persistence of this neuromuscular system is androgen-dependent, however, and the muscles and motoneurons degenerate in females during a perinatal cell death period (Cihak et al., 1970; Nordeen et al., 1985). As a result, adult male rats have $\sim 4$ times as many SNB motoneurons as do females (Breedlove and Arnold, 1980). Although this neuromuscular system has been studied most intensively in rats, a significant sex difference in the number of motoneurons innervating the bulbocavernosus muscle (male $>$ female) exists in many mammals including mice, gerbils, hyenas, monkeys, dogs, and humans (Ueyama et al., 1985; Forger and Breedlove, 1986; Wee and Clemens, 1987; Ulibarri et al., 1995; Forger et al., 1996).

$\mathrm{BC} / \mathrm{LA}$ muscle size and SNB motoneuron number can be permanently masculinized in female rats and mice by treating them with the androgen testosterone during perinatal development (Breedlove and Arnold, 1983; Nordeen et al., 1985; Wagner and Clemens, 1989a). Testosterone apparently acts directly at the $\mathrm{BC} / \mathrm{LA}$ muscles, with sparing of SNB motoneurons an indirect consequence of hormone action at the muscle (Fishman and Breedlove, 1988; Fishman et al., 1990; Freeman et al., 1997; Jordan et al., 1997). We have reported recently that ciliary neurotrophic factor (CNTF) administered to perinatal female rats can also slow or prevent SNB motoneuron death (Forger et al., 1993; Bengston et al., 1996). Moreover, CNTF receptors are expressed by both SNB motoneurons and their target muscles (Forger et al., 1997; Xu and Forger, 1997). This raises the possibility that some effects of testosterone on the SNB system may be 
mediated via a neurotrophic factor such as CNTF. To determine whether CNTF or the $\alpha$-component of its receptor, CNTFR $\alpha$, is normally involved in sexually dimorphic development of the SNB, we have examined SNB motoneuron number and BC/LA muscle size in CNTF and CNTFR $\alpha+/+$ and $-/-$ mice.

\section{MATERIALS AND METHODS}

Animals. CNTF knockout mice (CNTF -/-) and their wild-type siblings $(\mathrm{CNTF}+/+)$ were generously provided by Dr. Hans Thoenen (Max-Planck Institute). CNTF gene expression was abolished in 129/SVC57BL/6 mice by homologous recombination as described previously (Masu et al., 1993). CNTF - /- mice develop normally and exhibit only modest neuromuscular deficits in adulthood (Masu et al., 1993). In the present study, adult mice, 3-21 months of age, were examined.

CNTF acts through a three-part, cell surface receptor complex consisting of a ligand-binding $\alpha$ component (CNTFR $\alpha)$ and the signal transducing components LIFR $\beta$ and gp130 (Davis et al., 1993a; Stahl and Yancopoulos, 1994). Expression of CNTFR $\alpha$ is restricted primarily to cells of the nervous system and to striated muscle, and expression of CNTFR $\alpha$ is required for direct CNTF action (Ip et al., 1993). Mice heterozygous for a mutation of CNTFR $\alpha(\operatorname{CNTFR} \alpha+/-)$ were generated as a cross between 129 and C57BL/6 strains (DeChiara et al., 1995). The progeny of heterozygous matings are $\sim 25 \%$ wild-type (CNTFR $\alpha$ $+/+), 50 \%$ heterozygous (CNTFR $\alpha+/-)$, and $25 \%$ homozygous knockouts (CNTFR $\alpha-/-)$. Only wild-type and homozygous knockouts were examined in the present study, except where indicated. Although apparently normal in size and appearance at birth, mice lacking expression of CNTFR $\alpha$ fail to suckle and die within $24 \mathrm{hr}$ (DeChiara et al., 1995). All CNTFR $\alpha+/+$ and $-/-$ mice in the present study, therefore, were killed on postnatal day 1 . The sex of each pup was confirmed by inspection of the gonads, and the CNTFR $\alpha$ mutant genotype was determined by Southern blotting of tail DNA as in DeChiara et al. (1995).

Motoneuron counts. Motoneurons were counted in the three major motor pools of the lower lumbar spinal cord: the SNB, the dorsolateral nucleus (DLN), and the retrodorsolateral nucleus (RDLN). The SNB and DLN innervate sexually dimorphic muscles associated with the penis, and both of these nuclei undergo androgen-regulated cell death during perinatal development. The RDLN innervates primarily muscles of the foot, which are present and similar in both sexes. RDLN motoneuron number is not sexually dimorphic or altered by early hormone treatments (Jordan et al., 1982). In rats, SNB motoneurons reside in a relatively tight cluster just below the central canal. As has been reported previously for house mice (Wagner and Clemens, 1989b), we found that many SNB motoneurons in the mouse strains used in this study extended more ventrally and ventro-laterally along the gray-white border of the medial ventral horn. Retrograde tracing (see below) confirmed that these motoneurons innervate the perineal muscles, and we therefore included these cells in our counts of the SNB.

Thirty-two adult CNTF $+/+$ and $-/-$ mice were perfused and postfixed with $4 \%$ paraformaldehyde in PBS. The lumbosacral portion of the spinal cord was removed, cryoprotected by soaking in a $10 \%$ sucrose solution overnight, and frozen-sectioned in the coronal plane at a thickness of $40 \mu \mathrm{m}$. Alternate sections were mounted on separate slides and stained with thionin. SNB motoneurons were counted bilaterally, and the RDLN was counted unilaterally, in alternate sections. Only those motoneurons in which the nucleus was visible were included in the counts. SNB raw counts were multiplied by 2 and RDLN counts were multiplied by 4 to estimate the total bilateral number of motoneurons in each pool. SNB motoneuron size was determined for all CNTF $+/+$ and $-/-$ animals; cell size in the RDLN was determined for 14 randomly chosen CNTF $-/-$ and wild-type males. The soma and nucleus of all SNB and RDLN motoneurons were traced by camera lucida from four sections equally spaced throughout the rostro-caudal extent of each cell group. Cross-sectional areas were determined from the tracings using a digitizing pad linked to a computer.

Thirty-six CNTFR $\alpha+/+$ and $-/-$ newborns were decapitated and immersion fixed in Bouin's solution for at least $2 \mathrm{~d}$. The lumbosacral spinal cords were then embedded in paraffin, cross-sectioned at $12 \mu \mathrm{m}$, and stained with thionin. Motoneuron number in the SNB and RDLN of all mice was counted bilaterally in alternate sections. We later counted the DLN bilaterally in alternate sections in a cohort of 14 mice (see Results). Only cells in which both a nucleus and a nucleolus were clearly present were included in the motoneuron counts of newborns. The size of the somata, nuclei, and nucleoli of SNB motoneurons was determined for 20 randomly selected CNTFR $\alpha+/+$ and $-/-$ animals, as described above. All motoneuron counts and cell size measurements were performed on slides coded to conceal the subject's sex and genotype.

Determination of muscle size. The $\mathrm{BC} / \mathrm{LA}$ muscle complex was dissected out of adult CNTF $+/+$ and $-/-$ males, trimmed, and weighed by an individual blind to the mutant genotype of the animal. Size of the $\mathrm{BC} / \mathrm{LA}$ muscle complex of CNTFR $\alpha+/+$ and $-/-$ newborns of both sexes was determined from serial sections through the perineum. The perineal region was embedded in paraffin and cut in cross section with respect to the rectum at a thickness of $7 \mu \mathrm{m}$. Sections were stained with trichrome (modified Gomori's method), and camera lucida tracings of the LA and BC muscles were made from every 8th section. Muscle cross-sectional areas were determined on a digitizing pad linked to a computer, and cross-sectional areas throughout the extent of both muscles were summed to determine total BC and LA size in each animal.

Retrograde labeling of motoneurons. Cholera toxin conjugated to horseradish peroxidase [CT-HRP; $1 \mu \mathrm{l}$ of a $0.2 \%(\mathrm{w} / \mathrm{v})$ aqueous solution, List Biological Labs] was injected into the $\mathrm{BC}$ muscles, or was simply injected subcutaneously in the region of the $\mathrm{BC} / \mathrm{LA}$ and ischiocavernosus muscles, of newborn CNTFR $\alpha+/+$, CNTFR $\alpha+/-$, and CNTFR $\alpha-/-$ mice. In several cases, a second, $0.5 \mu$ l, injection was made into the flexor digitorum brevis muscle of the foot. Pups were returned to dams and, after a $4.5-6.0 \mathrm{hr}$ survival time, overdosed with chlorapent anesthesia. A tail sample was taken for Southern blot analysis of the CNTFR $\alpha$ genotype, and the animals were perfused with PBS followed by $1 \%$ paraformaldehyde $/ 1.25 \%$ glutaraldehyde. Spinal cords were removed, post-fixed in paraformaldehyde/glutaraldehyde for $3 \mathrm{hr}$, and then immersed in $10 \%$ sucrose overnight. Cords were frozen-sectioned at $30 \mu \mathrm{m}$, and freefloating sections were incubated with tetramethylbenzidine according to the method of Mesulam (1978).

Statistical analyses. Means \pm SEM are presented throughout. Motoneuron number in each motor pool (SNB, DLN, RDLN) was analyzed by two-way ANOVA (sex by knockout status). Mass of the BC/LA muscle complex in male $\mathrm{CNTF}+/+$ and $-/-$ males, as well as $\mathrm{BC}$ and LA muscle sizes of CNTFR $\alpha+/+$ and $-/-$ animals, was compared by independent two-tailed $t$ tests. Differences in motoneuron size between groups were evaluated in two ways. First, in accord with all previously published papers on the SNB neuromuscular system, the mean motoneuron size in the RDLN and SNB of each animal was determined, and for the subsequent ANOVA, $n=$ number of animals. The means and SEs reported in Table 1 have been calculated in this way. Next, to compare our results with previous studies on CNTF and CNTFR $\alpha$ knockout mice (Masu et al., 1993; DeChiara et al., 1995), we analyzed cell size data with the individual motoneuron as the unit of measure, and $n=$ number of motoneurons traced. Correlations between age and motoneuron number were determined by Pearson's correlation coefficient.

\section{RESULTS}

\section{Motoneuron number is not affected by deletion of the CNTF gene}

The number of SNB motoneurons in $\mathrm{CNTF}+/+$ and $-/-$ mice is shown in Figure $1 A$. As expected, wild-type males had many more SNB cells than did females $(p<0.0001)$. The normal sex difference in SNB motoneuron number was also observed in the CNTF $-/-$ animals $(p<0.0001)$. Thus, deletion of the CNTF gene did not affect the development of sexual dimorphism in the SNB. There was no main effect of the gene disruption on SNB motoneuron number, nor was there a sex $\times$ genotype interaction ( $p>0.50$ in both cases). In other words, deletion of the CNTF gene did not affect SNB cell number when sex was ignored as a variable, and the gene deletion was equally without effect in males and females.

Motoneuron counts in the RDLN exhibited no sex difference, no effect of the CNTF gene knockout, and no sex $\times$ genotype interaction (Fig. 2B). There was a trend toward slightly lower RDLN cell counts in females of both genotypes, but this was not statistically significant ( $p=0.12$ ). Masu et al. (1993) have reported that the number of motoneurons in the brainstem facial nucleus of CNTF $-/-$ mice declines with age and that by 28 weeks of age $\mathrm{CNTF}-/-$ mice exhibit a statistically significant 

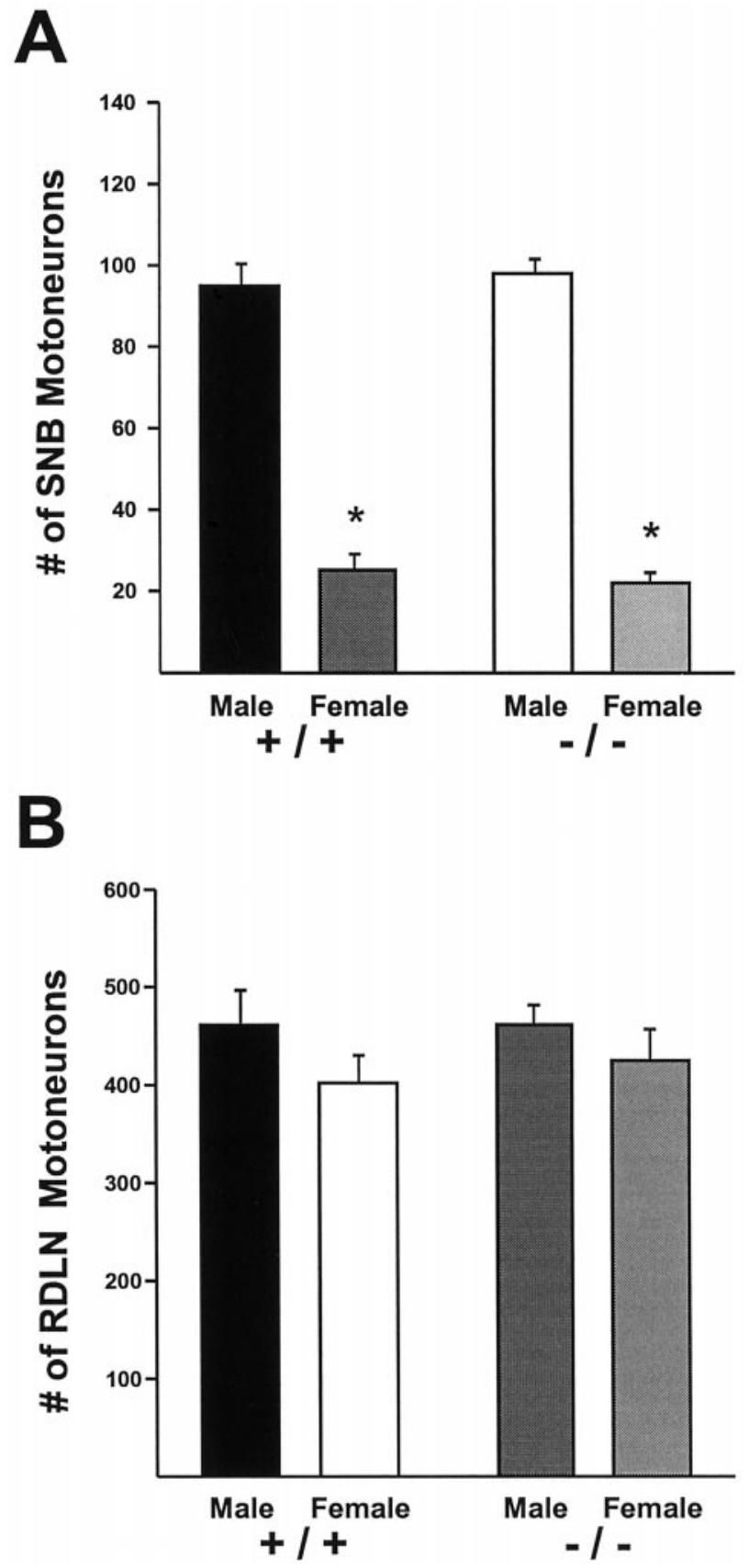

Figure 1. Motoneuron counts in adult $\mathrm{CNTF}+/+$ and $-/-$ mice of both sexes. $A$, The number of motoneurons in the SNB is sexually dimorphic in both wild-type and knockout animals ( $\left.{ }^{*} p<0.0001\right)$, and there is no effect of the gene knockout on the magnitude of the sex difference. $B$, There is no effect of sex or of genotype on the number of motoneurons in the RDLN.

reduction in motoneuron number. The mice in the present study ranged from 3 to 21 months of age, and mean age did not differ between the $\mathrm{CNTF}-/-$ and $\mathrm{CNTF}+/+$ groups $(\mathrm{CNTF}+/+$ : $16.8 \pm 1.2$ months; $\mathrm{CNTF}-/-: 14.6$ months \pm 1.7 months; $p>$ $0.25)$. Confirming the observation that motoneuron number declines with age in CNTF -/- mice (Masu et al., 1993), age was negatively correlated with motoneuron number in the RDLN and SNB of CNTF $-/-$ mice, although this was statistically significant only for the SNB (RDLN: $r=-0.368, p=0.15$; SNB: $r=$ $-0.552, p<0.03)$. However, when analysis of motoneuron num- ber is restricted to animals over 6 months of age the pattern of results was the same as that described above, i.e., there was no significant effect of the CNTF gene deletion on motoneuron number in the RDLN or SNB ( $p>0.80$ in both cases).

\section{Motoneuron and muscle size is not affected in CNTF knockout mice}

As expected from previous studies (Breedlove and Arnold, 1981; Wagner and Clemens, 1989a), adult males had larger SNB somata $(p<0.005)$ and nuclei $(p<0.05)$ than did females (somata males: $654 \pm 18 \mu \mathrm{m}^{2}$; somata females: $543 \pm 32 \mu \mathrm{m}^{2}$; nuclei males: $216 \pm 9 \mu \mathrm{m}^{2}$; nuclei females: $180 \pm 13 \mu \mathrm{m}^{2}$ ). However, there was no effect of the CNTF gene deletion on the size of motoneuronal somata or nuclei in the SNB $(p>0.70$ in both cases; data not shown). Similarly, RDLN soma size was not different in CNTF $-/-$ and CNTF $+/+$ animals ( $616 \pm 49$ versus $618 \pm 59 \mu \mathrm{m}^{2}$, respectively), nor was there an effect of the gene knockout on mean RDLN nuclear size $(206 \pm 26$ and $199+37$ $\mu \mathrm{m}^{2}$ for $-/-$ and $+/+$ males, respectively). This was true regardless of which of the two methods was used for cell size analysis (see Materials and Methods). Thus, our observations in the SNB and RDLN differ from the previous report of a decrease in soma size, and a transient increase in cell nuclear size, in spinal motoneurons of CNTF -/- mice (Masu et al., 1993).

The BC/LA muscle complex was compared in $7 \mathrm{CNTF}+/+$ and $13 \mathrm{CNTF}-/-$ animals. The muscles were well developed and appeared grossly normal in both groups; BC/LA wet weight was not significantly different $(\mathrm{CNTF}+/+: 151 \pm 12 \mathrm{gm}$; CNTF $-/-: 140 \pm 7 \mathrm{gm} ; p=0.40)$.

\section{Deletion of CNTFR $\alpha$ eliminates the sex difference in SNB motoneuron number}

Motoneuron number in $\operatorname{CNTFR} \alpha+/+$ and $-/-$ animals was analyzed in two separate cohorts of animals. The pattern of results was the same, and the data from these two replications have been combined in the following discussion. SNB cell number was sexually dimorphic on the day of birth in CNTFR $\alpha+/+$ mice, with males possessing $62 \%$ more motoneurons than females $(p<0.001)$ (Fig. 2A). The magnitude of this sex difference is not as large as was observed in the adult mice described above, presumably because females continue to lose motoneurons in the SNB during the first several postnatal days (Nordeen et al., 1985; Wagner and Clemens, 1989a). In contrast, there was no sex difference in CNTFR $\alpha-/-$ newborns. Male CNTFR $\alpha-/-$ mice had fewer than half as many SNB cells than did wild-type males $(p<0.0001)$ and did not differ from CNTFR $\alpha-/-$ females on this measure $(p>0.20)$ (Fig. $2 A)$.

There was no effect of sex on the number of RDLN motoneurons of CNTFR $\alpha+/+$ and $-/-$ animals $(p>0.10)$. Motoneuron number in the RDLN was reduced by $\sim 20 \%$ in knockout mice of both sexes (Fig. 2B) $(p<0.0001)$, in agreement with the previous report of a significant reduction in the number of motoneurons throughout the lumbar spinal cord in newborn CNTFR $\alpha-/-$ animals (DeChiara et al., 1995). We reasoned that if the reduction in SNB motoneuron number seen in $\mathrm{CNTFR} \alpha-/-$ males was caused simply by generalized motoneuron death in CNTFR $\alpha$ knockouts, then the mean ratio of SNB motoneuron number to RDLN motoneuron number would be the same in the knockout and wild-type animals. This was in fact true for CNTFR $\alpha+/+$ and $-/-$ females $(p>0.40)$ (Fig. $2 C$ ). However, reductions in SNB cell number of CNTFR $\alpha-/-$ males were not proportional to reductions in the RDLN, and the $\mathrm{SNB} / \mathrm{RDLN}$ ratio was 

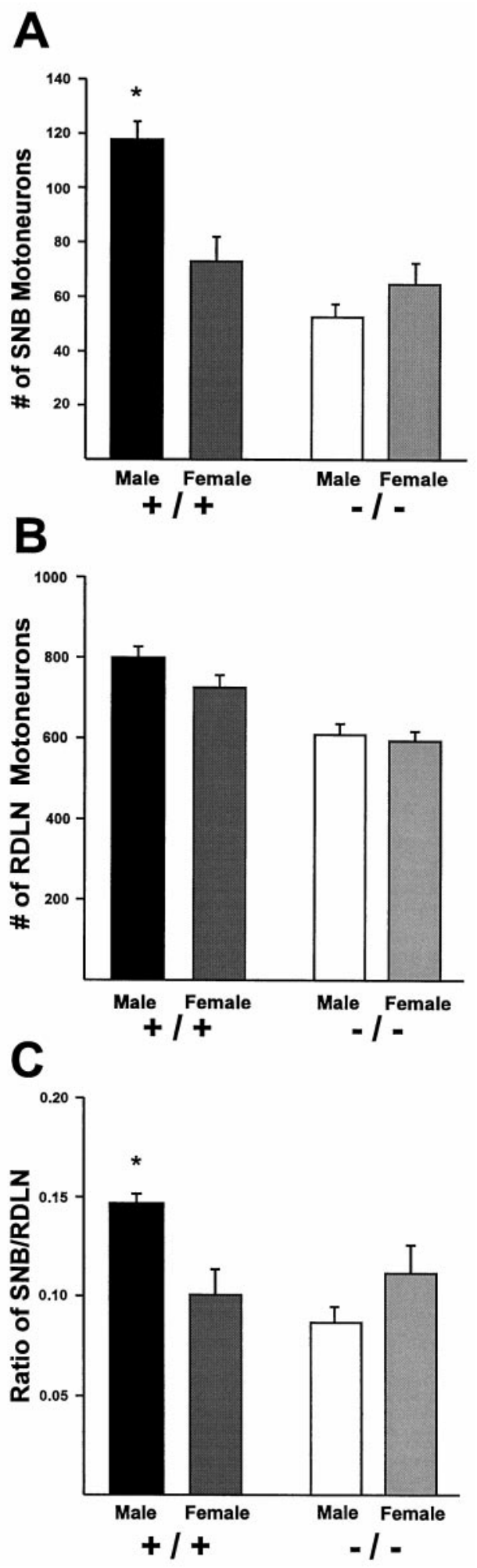

Figure 2. Motoneuron counts in CNTFR $\alpha+/+$ and $-/-$ mice of both sexes. $A$, SNB motoneuron number is sexually dimorphic in newborn wild-type mice ( $\left.{ }^{*} p<0.001\right)$, but CNTFR $\alpha-/-$ males have no more SNB motoneurons than do $-/-$ or $+/+$ females. $B$, The number of RDLN motoneurons was reduced by $\sim 20 \%$ in both knockout males and females ( $p<0.0001$ for main effect of the gene knockout). $C$, The ratio SNB motoneuron number to RDLN motoneuron number was significantly greater in wild-type males than in CNTFR $\alpha-/-$ males or in females $\left({ }^{*} p<0.01\right.$ in each case). Knockout males and females did not differ on this measure. significantly lower in CNTFR $\alpha-/-$ males than in CNTFR $\alpha$ $+/+$ males $(p=0.001)$. The $\mathrm{SNB} / \mathrm{RDLN}$ ratio of knockout males did not differ significantly from that of wild-type or knockout females.

\section{Motoneuron size in CNTFR $\alpha+/+$ and $-/-$ mice}

The mean size of SNB motoneurons was determined for five animals in each of the four groups (see Table 1). There was no significant effect of sex or knockout status on soma, nuclear, or nucleolar size when the mean cell size of each animal was used as the unit of analysis. Using individual motoneurons as the unit of analysis, DeChiara et al. (1995) observed a reduction in the soma size of spinal motoneurons in CNTFR $\alpha-/-$ animals on postnatal day 1 . When the present data are analyzed as in DeChiara et al. (1995), the $7.5 \%$ reduction in SNB soma size of CNTFR $\alpha$ $-/-$ males relative to their wild-type counterparts is statistically significant $(p<0.05)$, although we do not see a similar effect in females.

\section{BC/LA size is normal in CNTFR $\alpha-/-$ males, but the $\mathrm{LA}$ is reduced in CNTFR $\alpha-/-$ females}

Size of the BC and LA muscles, targets of SNB motoneurons, was determined from sections through the perineal area of 8 males and 13 females (Fig. 3). There was no difference in LA or BC muscle size between CNTFR $\alpha$ wild-type and $-/-$ males $(p>$ 0.50 in both cases) (Figs $3,4 A$ ). Thus, the BC/LA muscles of knockout males appear to develop normally, despite the fact that motoneuron number is greatly reduced in the SNB of these animals. The BC and LA muscles were much smaller in females than in males (Fig. 4; note the difference in scale on the ordinates in $A$ and $B$ ), and very little BC muscle could be identified definitively in any female. Size of the BC did not differ between CNTFR $\alpha+/+$ and $-/-$ females $(p>0.50)$, whereas the LA muscle was significantly larger in $\operatorname{CNTFR} \alpha+/+$ than in CNTFR $\alpha-/-$ females (Fig. 4B) $(p<0.005)$.

\section{CT-HRP labels the same motor pools in CNTFR $\alpha+/+$,} $+/-$, and $-/-$ animals

We next asked whether SNB motoneurons of CNTFR $\alpha-/-$ males are in contact with the BC/LA muscles and whether motoneurons innervating the $\mathrm{BC} / \mathrm{LA}$ are restricted to the expected SNB position. Injections of CT-HRP into the perineal muscles labeled motoneurons in both the SNB and the DLN, with the DLN exhibiting particularly heavy labeling (Fig. 5). This pattern of CT-HRP accumulation presumably reflects uptake by motor nerve terminals in the $\mathrm{BC} / \mathrm{LA}$ and ischiocavernosus (IC) muscles, because the $\mathrm{BC} / \mathrm{LA}$ and IC are immediately adjacent to one another and together form a complex of muscles attached to

Table 1. Size $\left(\mu \mathrm{m}^{2}\right)$ of SNB motoneurons in newborn CNTFR $\alpha+/+$ and CNTFR $\alpha-/-$ mice

\begin{tabular}{lllllr} 
& Somata & Nuclei & Nucleoli & $N_{\mathrm{a}}$ & $N_{\mathrm{m}}$ \\
\hline Males & & & & & \\
CNTFR $\alpha+/+$ & $160 \pm 11$ & $74 \pm 7$ & $3.2 \pm 0.3$ & 5 & 105 \\
CNTFR $\alpha-/-$ & $148 \pm 6$ & $78 \pm 7$ & $3.5 \pm 0.9$ & 5 & 99 \\
Females & & & & & \\
CNTFR $\alpha+/+$ & $146 \pm 9$ & $78 \pm 4$ & $3.7 \pm 0.7$ & 5 & 95 \\
CNTFR $\alpha-/-$ & $150 \pm 3$ & $75 \pm 4$ & $3.8 \pm 0.5$ & 5 & 97
\end{tabular}

Values are mean \pm SEM. Reported means were calculated by averaging the mean cell size of each animal within the group. $N_{\mathrm{a}}$, Number of animals examined in each group; $N_{\mathrm{m}}$, total number of motoneurons traced. 


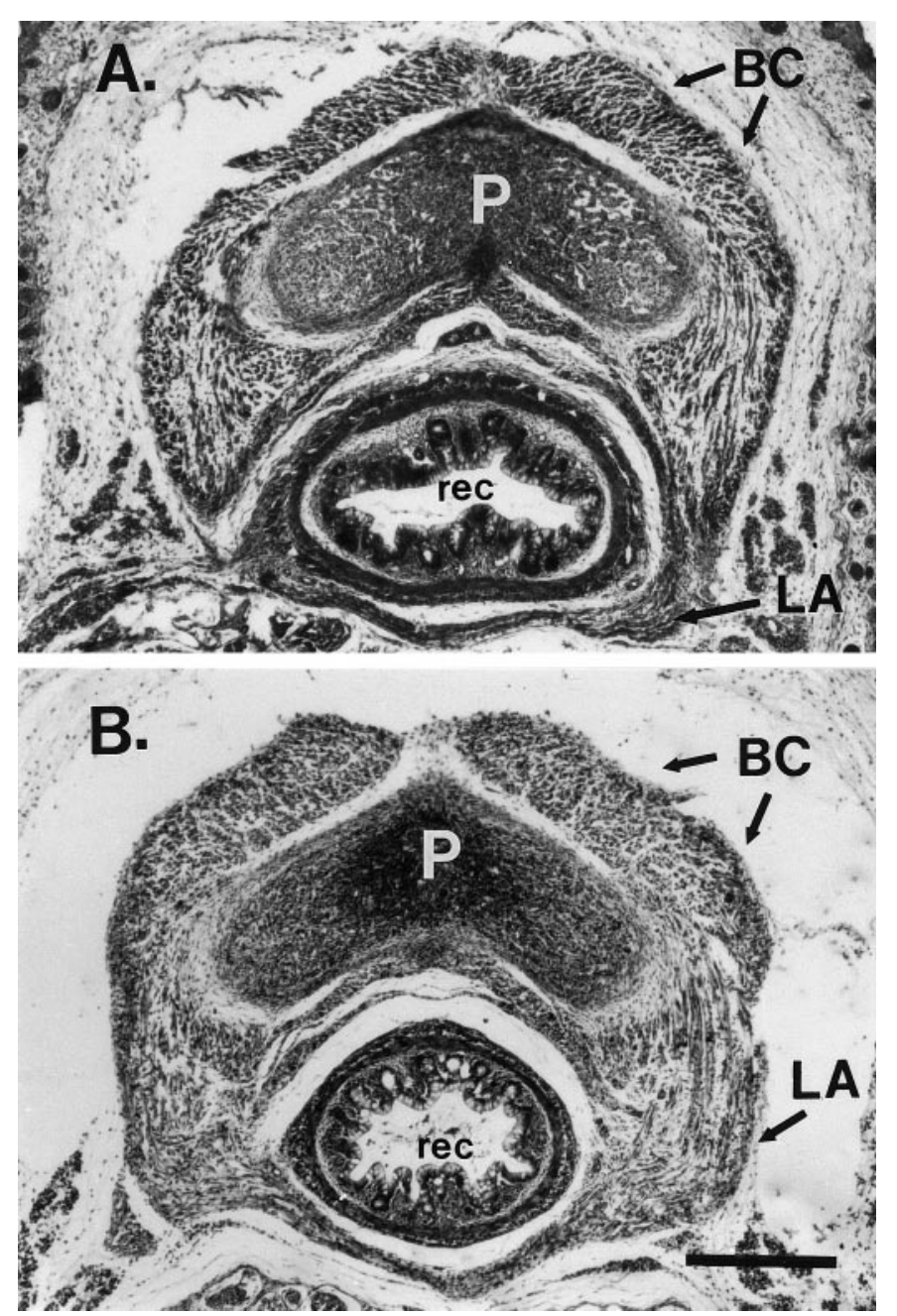

Figure 3. Cross sections through the perineums of CNTFR $\alpha+/+(A)$ and CNTFR $\alpha-/-(B)$ males. These sections were taken from mice with overall LA and $\mathrm{BC}$ muscle sizes close to their group means and are the single section from each animal with the greatest area of combined $\mathrm{BC}$ and LA. Dorsal is down. $P$, Base of penis; rec, rectum; $L A$, levator ani; $B C$, bulbocavernosus. Scale bar, $300 \mu \mathrm{m}$.

the base of the penis. The pattern of labeled motoneurons was the same for CNTFR $\alpha+/+,+/-$, and $-/-$ animals. In no case did we observe an anomalous projection to the perineal muscles in the knockouts. Injections of CT-HRP into the flexor digitorum brevis labeled motoneurons in the ipsilateral RDLN and, in some cases, nearly all RDLN motoneurons were labeled (Fig. 5A). Thus, as in the rat, the RDLN of mice appears to innervate primarily intrinsic muscles of the foot.

\section{The "missing" SNB motoneurons in CNTFR $\alpha-/-$ males are not in the DLN}

In the rat, motoneurons that eventually form the SNB originate in the region of the DLN. They then undergo a late, secondary migration into the more medial, SNB position (Sengelaub and Arnold, 1986). Under certain perinatal hormone conditions, the $\mathrm{BC} / \mathrm{LA}$ muscles can become innervated by motoneurons in the DLN (Breedlove, 1985; Sengelaub and Arnold, 1989). Because of the common developmental history of SNB and DLN motoneurons, and the robust labeling of the DLN after perineal CT-HRP injections observed above, we evaluated the possibility that the "missing" SNB motoneurons of CNTFR $\alpha-/-$ males might be

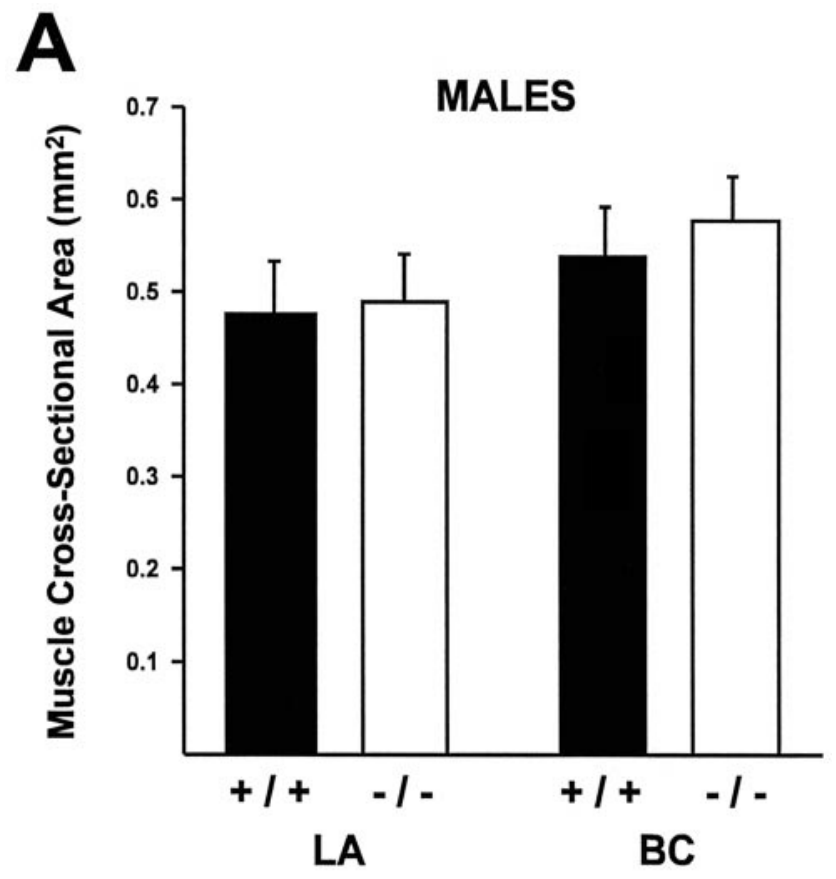

B

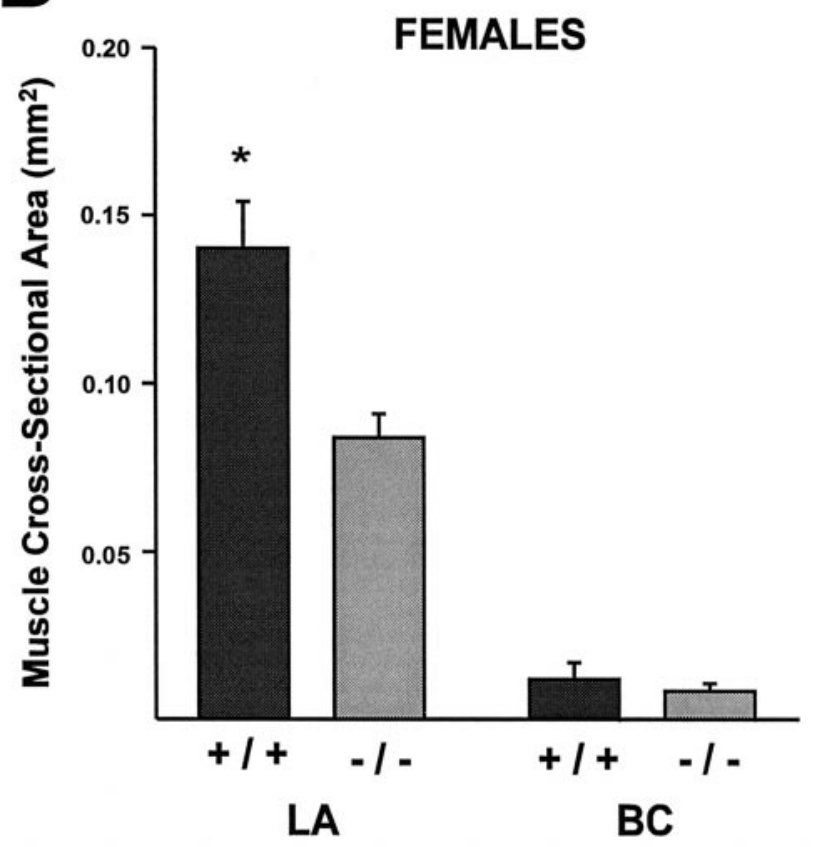

Figure 4. Size of the BC and LA muscles in CNTFR $\alpha+/+$ and $-/-$ animals. $A$, There was no effect of the gene knockout on the size of the LA or BC of males. $B$, The LA was significantly larger in CNTFR $\alpha+/+$ than in $-/-$ females $(* p<0.005)$.

located in the DLN. However, counts of the DLN in thioninstained sections reveal that $\operatorname{CNTFR} \alpha-/-$ males have significantly fewer DLN motoneurons than CNTFR $\alpha+/+$ males $(206 \pm 30$ vs $310 \pm 25 ; p<0.02)$ and have no more DLN motoneurons than CNTFR $\alpha-/-$ or $+/+$ females $(238 \pm 22$ and $232 \pm 23$, respectively; $p>0.40$ in both cases). Thus, the pattern of motoneuron number in the SNB and DLN, two androgendependent cell groups, is the same. The reduction of SNB cell 
A.

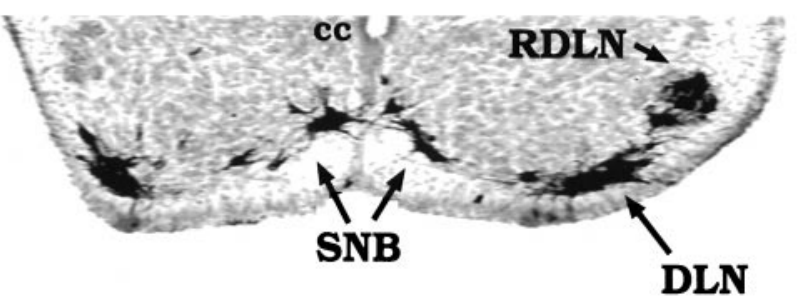

B.

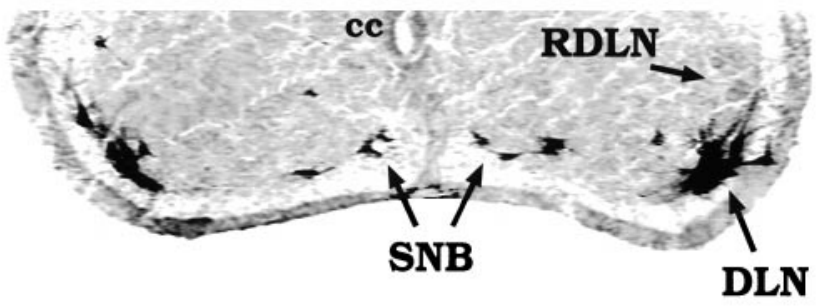

Figure 5. Photomicrographs of the ventral horn of the spinal cord of CNTFR $\alpha+/+(A)$ and CNTFR $\alpha-/-(B)$ male mice, demonstrating retrograde labeling of motoneurons. CT-HRP was injected on the day of birth, and animals were killed $6 \mathrm{hr}$ later. Injections were made into the perineums of both animals, labeling motoneurons in the $D L N$ and $S N B$. The flexor digitorum brevis of the right foot of the CNTFR $\alpha+/+$ male was also injected, resulting in the labeling of motoneurons in the ipsilateral $R D L N(A)$. Dorsal is up. $c c$, Central canal. Scale bar, $250 \mu \mathrm{m}$.

number in CNTFR $\alpha-/-$ males cannot be explained by the inability of motoneurons to migrate from the DLN.

\section{DISCUSSION}

The sexually dimorphic SNB neuromuscular system appeared completely normal in mice lacking CNTF. In contrast, the expected sex difference in SNB motoneuron number was not seen in newborn mice lacking the CNTF receptor. Normal, sexually dimorphic development of the $\mathrm{BC}$ and LA target muscles was observed in both CNTF and CNTFR $\alpha-/-$ males. These observations have at least three implications for understanding the development of sexual dimorphism in this system: (1) the maintenance of elevated numbers of SNB motoneurons in male mice depends on a functional $\operatorname{CNTFR} \alpha$; (2) the survival of the $\mathrm{BC} / \mathrm{LA}$ target muscles is not sufficient to ensure maintenance of SNB motoneurons; and (3) CNTF itself is not the relevant ligand for CNTF receptor-dependent development of sexual dimorphism in the SNB. Each of these points will be considered in turn below.

Fewer SNB motoneurons were present in CNTFR $\alpha-1-$ males than in CNTFR $\alpha+/+$ males, and this difference greatly exceeded generalized motoneuron loss in the knockouts. The most straightforward explanation of our results is that many SNB cells of males died in the absence of CNTFR $\alpha$. Because the survival of SNB motoneurons is normally regulated by testosterone, these results indicate that hormone effects on SNB cell death could involve a pathway that requires signaling through the CNTF receptor. This might be true if, for example, testosterone normally maintains the production of a CNTF-like trophic molecule from BC/LA muscles; in the absence of CNTF receptors on SNB nerve terminals, the normal response to testosterone then would be blocked. CNTF receptors also might be required to mediate the reception of trophic support from neural afferents to SNB motoneurons.

Alternatively, it could be argued that as many SNB motoneurons survive in CNTFR $\alpha-/-$ males as in $+/+$ males, but that many of the SNB cells in the knockouts are not distinguishable as motoneurons and, therefore, were missed in our counts. This might be true if, for example, SNB motoneurons of knockout males were severely shrunken or altered in phenotype. We might also fail to accurately assess SNB cell number if deletion of the CNTFR $\alpha$ gene affected motoneuronal migration and the motoneurons were not in their usual location within the spinal cord. These explanations seem unlikely because those SNB motoneurons that were counted in knockout males were $93 \%$ as large as those in wild-type animals. In addition, CT-HRP injections into the perineum retrogradely labeled motoneurons in the SNB and DLN in both the CNTFR $\alpha+/+$ and the $-/-$ mice. At least within the confines of the lower lumbar cord, we did not observe labeled motoneurons in an anomalous position, nor was there evidence of greater numbers of motoneurons in the DLN of knockout males, which might indicate an effect on migration.

On the other hand, we cannot rule out the possibility that fewer SNB motoneurons were initially generated in $\operatorname{CNTFR} \alpha-/-$ animals. It will be of interest in future experiments to examine fetal mice to determine whether the same number of SNB and DLN motoneurons are present before the cell death period in CNTFR $\alpha-/-$ and wild-type animals.

Previous studies have established that manipulations that rescue the developing BC/LA muscles generally also spare SNB motoneurons. Treatment of female rats or mice with testosterone around the time of birth leads to permanent masculinization of $\mathrm{BC} / \mathrm{LA}$ muscle size and a concomitant masculinization of SNB motoneuron number (Cihak et al., 1970; Breedlove and Arnold, 1983; Wagner and Clemens, 1989a). Mutations that render the androgen receptor nonfunctional result in the absence of $\mathrm{BC}$ muscles and a feminine number of SNB motoneurons in affected male rats and mice (Breedlove and Arnold, 1981; Olsen et al., 1988). Finally, in perinatal female rats, injections of CNTF prevent the death of both the SNB motoneurons and their target muscles (Forger et al., 1993, 1995). In each case, rescue of BC/LA muscles is accompanied by rescue of SNB motoneurons, and it is not clear whether muscle persistence per se is sufficient for SNB motoneuron survival or whether specific signals from the BC/LA muscles are required for the sparing of SNB motoneurons.

In the present study, the BC/LA muscles of CNTFR $\alpha-/-$ males were indistinguishable in size and appearance from those of wild-type controls, yet fewer than half as many SNB motoneurons were observed in the mutants. At least some of those SNB motoneurons present on postnatal day 1 in $\operatorname{CNTFR} \alpha-/-$ mice were in contact with the perineal muscles, as demonstrated by the ability to label them retrogradely by CT-HRP injections delivered to the perineum. CNTFR $\alpha-/-$ mice do not survive beyond postnatal day 1 , and it is possible that the $\mathrm{BC} / \mathrm{LA}$ muscle would eventually degenerate in the knockout males if the animals' survival could be prolonged. The BC/LA muscles of CNTFR $\alpha$ $-/-$ males also may have subtle defects in morphology or physiology not evident from a relatively crude analysis of muscle size. Nonetheless, it seems clear that the simple presence of the $\mathrm{BC} / \mathrm{LA}$ target muscles does not ensure normal SNB development. Rather, specific signals from the BC/LA muscles apparently are required for $\mathrm{SNB}$ motoneuron survival, and the 
CNTF receptor may play a necessary part in the signaling cascade.

Although targeted disruption of the CNTFR $\alpha$ gene did not affect development of the BC/LA muscles in male mice, the size of the LA was significantly reduced in CNTFR $\alpha-/-$ females. This suggests a role for CNTFR $\alpha$ in development of the female LA. Possibly, signaling through the CNTF receptor ameliorates the atrophy of the androgen-dependent LA muscle when androgen levels are low, as in perinatal females; but CNTFR $\alpha$ is not required for normal LA development provided that androgen levels are adequately high. It is not clear whether CNTFR $\alpha$ might also affect the timing of $\mathrm{BC}$ muscle degeneration, because even in wild-type females the $\mathrm{BC}$ was nearly absent on the day of birth.

CNTFR $\alpha$ expression in skeletal muscle is markedly upregulated after denervation (Davis et al., 1993b), and administration of CNTF to adult rats can slow the muscle atrophy induced by denervation (Helgren et al., 1994). CNTF also prevents the atrophy of the $\mathrm{BC} / \mathrm{LA}$ muscles that normally occurs in perinatal female rats (Forger et al., 1993), and CNTFR $\alpha$ message is upregulated in the perinatal $\mathrm{BC} / \mathrm{LA}$ after androgen blockade (Xu and Forger, 1997). These findings suggest that CNTF receptor expression in striated muscles plays an important trophic role in times of muscle atrophy, such as after denervation or during androgen deprivation of androgen-dependent muscles. In normal, innervated striated muscle, however, CNTF can actually promote catabolism (Henderson et al., 1994; Martin et al., 1996). The reason for these different effects is not at all clear.

Several observations have led to the suggestion that CNTF itself is not a developmentally relevant ligand for the CNTF receptor, but that another, as yet unidentified ligand for CNTFR $\alpha$ exists and regulates motoneuron survival in development. The most compelling evidence for this view is that deletion of the CNTF gene in mice does not cause measurable motor defects until well into adulthood, whereas the deletion of CNTFR $\alpha$ results in a significant reduction of motoneuron number at birth and early postnatal mortality (Masu et al., 1993; DeChiara et al., 1995). The fact that CNTF lacks a classical signal sequence calls into question whether CNTF can even be secreted as a target-derived trophic factor (Lin et al., 1989; Stöckli et al., 1989) and has led to the suggestion that CNTF may instead have a role in the response to neural injury (Sendtner et al., 1992). In the present study, deletion of the CNTFR $\alpha$ gene had a detrimental effect on SNB motoneuron number in male mice, whereas deleting the gene for CNTF did not. These findings support the existence of a second ligand for CNTFR $\alpha$ and indicate an involvement of this second ligand in the sexually dimorphic development of perineal motoneurons.

\section{REFERENCES}

Bengston L, Lopez V, Watamura S, Forger NG (1996) Short- and longterm effects of ciliary neurotrophic factor on androgen-sensitive motoneurons in the lumbar spinal cord. J Neurobiol 31:263-273.

Breedlove SM (1985) Hormonal control of the anatomical specificity of motoneuron-to-muscle innervation in rats. Science 227:1357-1359.

Breedlove SM, Arnold AP (1980) Hormone accumulation in a sexually dimorphic motor nucleus in the rat spinal cord. Science 210:564-566.

Breedlove SM, Arnold AP (1981) Sexually dimorphic motor nucleus in the rat lumbar spinal cord: response to adult hormone manipulation, absence in androgen-insensitive rats. Brain Res 225:297-307.

Breedlove SM, Arnold AP (1983) Hormonal control of a developing neuromuscular system. II. Sensitive periods for the androgen-induced masculinization of the rat spinal nucleus of the bulbocavernosus. J Neurosci 3:424-432.

Chu-Wang I-W, Oppenheim RW (1978) Cell death of motoneurons in the chick embryo spinal cord. I. A light and electron microscopic study of naturally occurring and induced cell loss during development. J Comp Neurol 177:33-58.

Cihak R, Gutmann E, Hanzlikova V (1970) Involution and hormoneinduced persistence of the muscle sphincter (levator) ani in female rats. J Anat (Lond) 106:93-110.

Davis S, Aldrich TH, Stahl N, Pan L, Taga T, Kishimoto T, Ip NY, Yancopoulos GD (1993a) LIFR $\beta$ and gp130 as heterodimerizing signal transducers of the tripartite CNTF receptor. Science 260:1805-1808.

Davis S, Aldrich TH, Ip NY, Stahl N, Scherer S, Farruggella T, DiStefano PS, Curtis R, Panayotatos N, Gascan H, Chevalier S, Yancopoulos GD (1993b) Released form of CNTF receptor $\alpha$ component as a soluble mediator of CNTF response. Science 259:1736-1739.

DeChiara TM, Vejsada R, Poueymirou WT, Acheson A, Suri C, Conover JC, Friedman B, McClain J, Pan L, Stahl N, Ip NY, Kato A, Yancopoulos GD (1995) Mice lacking the CNTF receptor, unlike mice lacking CNTF, exhibit profound motor neuron deficits at birth. Cell 83:313-322.

Fishman RB, Breedlove SM (1988) Neonatal androgen maintains sexually dimorphic motoneurons in the absence of innervation. Muscle Nerve 11:553-560.

Fishman RB, Chism L, Firestone GL, Breedlove SM (1990) Evidence for androgen receptors in sexually dimorphic perineal muscles of neonatal male rats. Absence of androgen accumulation by the perineal motoneurons. J Neurobiol 21:694-704.

Forger NG, Breedlove SM (1986) Sexual dimorphism in human and canine spinal cord: role of early androgen. Proc Natl Acad Sci USA 83:7527-7531.

Forger NG, Roberts SL, Wong V, Breedlove SM (1993) Ciliary neurotrophic factor maintains motoneurons and their target muscles in developing rats. J Neurosci 13:4720-4726.

Forger NG, Wong V, Breedlove SM (1995) Ciliary neurotrophic factor arrests muscle and motoneuron degeneration in androgen-insensitive rats. J Neurobiol 28:354-362.

Forger NG, Frank LG, Breedlove SM, Glickman SE (1996) Sexual dimorphism of perineal muscles and motoneurons in spotted hyenas. J Comp Neurol 375:333-343.

Forger NG, Wagner CK, MacLennon J (1997) Expression of the CNTF receptor is androgen regulated in sexually dimorphic motoneurons. Soc Neurosci Abstr 23:628.

Freeman LM, Watson NV, Breedlove SM (1997) Androgen spares androgen-insensitive motoneurons from apoptosis in the spinal nucleus of the bulbocavernosus in rats. Hormones and Behavior 30:424-433.

Hamburger V (1975) Cell death in the development of the lateral motor column of the chick embryo. J Comp Neurol 160:535-546.

Harris AJ, McCaig CD (1984) Motoneuron death and motor unit size during embryonic development of the rat. J Neurosci 4:13-24.

Helgren ME, Squinto SP, Davis HL, Parry DJ, Boulton TG, Heck CS, Zhu Y, Yancopoulos GD, Lindsay RM, DiStefano PS (1994) Trophic effect of ciliary neurotrophic factor on denervated skeletal muscle. Cell 76:493-504.

Henderson JT, Senuik NA, Richardson PM, Gauldie J, Roder JC (1994) Systemic administration of ciliary neurotrophic factor induces cachexia in rodents. J Clin Invest 93:2632-2638.

Ip NY, Yancopoulos GD (1996) The neurotrophins and CNTF: two families of collaborative neurotrophic factors. Annu Rev Neurosci 19:491-515.

Ip NY, McClain J, Barrezueta NX, Aldrich TH, Pan L, Li Y, Weigand SJ, Friedman B, Davis S, Yancopoulos GD (1993) The alpha component of the CNTF receptor is required for signalling and defines potential CNTF targets in the adult and during development. Neuron 10:89-102.

Jordan CL, Breedlove SM, Arnold AP (1982) Sexual dimorphism and the influence of neonatal androgen in the dorsolateral motor nucleus of the rat lumbar spinal cord. Brain Res 249:309-314.

Jordan CL, Padgett B, Hershey J, Prins G, Arnold A (1997) Ontogeny of androgen receptor immunoreactivity in lumbar motoneurons and in the sexually dimorphic levator ani muscle of male rats. J Comp Neurol 379:88-98.

Lance-Jones C (1982) Motoneuron cell death in the developing lumbar spinal cord of the mouse. Dev Brain Res 4:473-479.

Lin L-FH, Mismer D, Lile JD, Armes LG, Butler ET, Vannice JL, Collins F (1989) Purification, cloning, and expression of ciliary neurotrophic factor (CNTF). Science 246:1023-1025.

Martin D, Merkel E, Tucker KK, McManaman JL, Albert D, Relton J, 
Russel D (1996) Cachectic effect of ciliary neurotrophic factor on innervated skeletal muscle. Am J Physiol 271:R1422-R1428.

Masu Y, Wolf E, Holtmann B, Sendtner M, Brem G, Thoenen H (1993) Disruption of the CNTF gene results in motor neuron degeneration. Nature 365:27-32.

Mesulam MM (1978) Tetramethyl benzidine for horseradish peroxidase neurohistochemistry: a non-carcinogenic blue reaction-product with superior sensitivity for visualizing neural afferents and efferents. J Histochem Cytochem 26:106-117.

McKenna KE, Nadelhaft I (1986) The organization of the pudendal nerve in the male and female rat. J Comp Neurol 248:532-549.

Nordeen EJ, Nordeen KW, Sengelaub DR, Arnold AP (1985) Androgens prevent normally occurring cell death in a sexually dimorphic spinal nucleus. Science 229:671-673.

Olsen KL, Wagner CK, Clemens LG (1988) Relationship between male sexual behaviors and dorsal medial spinal nucleus in androgeninsensitive Tfm mice. Soc Neurosci Abstr 14:283.

Oppenheim RW (1991) Cell death during development of the nervous system. Annu Rev Neurosci 14:453-501.

Oppenheim RW (1996) Neurotrophic survival molecules for motoneurons: an embarrassment of riches. Neuron 17:195-197.

Sachs BD (1982) Role of the rat's striated penile muscles in penile reflexes, copulation and the induction of pregnancy. J Reprod Fertil 66:433-443.

Schröder HD (1980) Organization of the motoneurons innervating the pelvic muscles of the male rat. J Comp Neurol 192:567-587.

Sendtner M, Stöckli KA, Thoenen H (1992) Synthesis and localization of ciliary neurotrophic factor in the sciatic nerve of the adult rat after lesion and during regeneration. J Cell Biol 118:139-148.

Sengelaub DR, Arnold AP (1986) Development and loss of early projections in a sexually dimorphic rat nucleus. J Neurosci 6:1613-1620.

Sengelaub DR, Nordeen EJ, Nordeen KW, Arnold AP (1989) Hor- monal control of neuron number in sexually dimorphic spinal nuclei of the rat. III. Differential effects of the androgen dihydrotestosterone. J Comp Neurol 280:637-644.

Stahl N, Yancopoulos GD (1994) The tripartite CNTF receptor complex: activation and signalling involves components shared with other cytokines. J Neurobiol 25:1454-1466.

Stöckli K, Lottspeich F, Sendtner M, Masiakowski P, Carroll P, Gotz R, Lindholm D, Thoenen H (1989) Molecular cloning, expression and regional distribution of rat ciliary neurotrophic factor. Nature 342:920-922.

Ueyama T, Mizuno N, Takahashi O, Nomura S, Arakawa H, Matsushima $\mathrm{R}$ (1985) Central distribution of efferent and afferent components of the pudendal nerve in macaque monkeys. J Comp Neurol 232:548-556.

Ulibarri C, Popper P, Micevych PE (1995) Motoneurons dorsolateral to the central canal innervate perineal muscles in the Mongolian gerbil. J Comp Neurol 356:225-237.

Wagner CK, Clemens LG (1989a) Perinatal modification of a sexually dimorphic motor nucleus in the spinal cord of the B6D2F1 house mouse. Physiol Behav 45:831-835.

Wagner CK, Clemens LG (1989b) Anatomical organization of the sexually dimorphic perineal neuromuscular system in the house mouse. Brain Res 499:93-100.

Wallach SJR, Hart BJ (1983) The role of the striated penile muscles of the male rat in seminal plug dislodgement and deposition. Physiol Behav 31:815-821.

Wee BEF, Clemens LG (1987) Characteristics of the spinal nucleus of the bulbocavernosus are influenced by genotype in the house mouse. Brain Res 424:305-310.

$\mathrm{Xu}$ J, Forger NG (1997) Androgen regulation of neurotrophic factor receptor gene expression in a sexually dimorphic neuromuscular system in rats. Soc Neurosci Abstr 23:628. 